\title{
Estratégias Organizacionais e o Desempenho das Empresas Que Realizaram Initial Public Offering (IPO)
}

\section{Organizational Strategies And Performance Of Initial Public Offering Companies (IPO)}

\author{
Vilmara Nilda dos Santos ${ }^{1}$, Thiago Bruno de Jesus Silva ${ }^{1}$, Luis Antonio Lay ${ }^{1}$, Leandro Nascimento ${ }^{1}$, \\ Gerson João Valeretto ${ }^{1}$
}

\author{
${ }^{1}$ Universidade Regional de Blumenal, FURB, Brasil \\ Correspondência: Thiago Bruno de Jesus Silva. Endereço: Rua São Paulo, 3250, Itoupava Seca, Blumenau, SC \\ CEP 89030080. Tel.: 5547 3221-6000. E-mail: thiagobruno.silva@yahoo.com.br
}

Recebido: 28 de janeiro de 2017 Aceito: 12 de abril de 2017 Publicado: 01 de novembro de 2017

DOI: http://dx.doi.org/10.21714/1679-18272017v15n1.p46-60

\begin{abstract}
Resumo
A estratégia utilizada pela empresa varia de acordo com a percepção que os administradores têm do ambiente organizacional e como reagem diante dele para que a empresa se mantenha competitiva. Neste sentido, este estudo objetivou analisar a influência das estratégias organizacionais, com base nas tipologias estratégicas de Miles e Snow (1978), no desempenho econômico-financeiro de empresas listadas na BM\&FBovespa que realizaram IPO. A pesquisa é exploratória, com abordagem quantitativa. Para analisar os dados, foram aplicados a Análise Multivariada (ANOVA) e o Teste de Tukey. Os resultados demonstram que a maioria das empresas foram identificadas como analisadoras e prospectoras, respectivamente. Verificou-se que as estratégias apresentam relação significante com os indicadores Imobilização do Patrimônio Líquido, Rentabilidade do Patrimônio Líquido, Rentabilidade do Ativo e Participação de Capitais de Terceiros, nos quais a estratégia prospectora apresentou melhores resultados em relação às demais. Assim, constatou-se que a maioria das empresas adotou a estratégia analisadora, no entanto as organizações que obtiveram melhores resultados foram as prospectoras.
\end{abstract}

Palavras-chave: Initial Public Offering (IPO); Estratégias Organizacionais; Miles e Snow (1978); Desempenho econômico-financeiro.

\begin{abstract}
This study aimed to analyze the influence of organizational strategies, based on the strategic typologies of Miles and Snow (1978), on the economic and financial performance of companies listed on BM \& FBovespa that carried out IPOs between 2008 and 2012. The research is exploratory, with an approach Quantitative. To analyze the data, we applied the Multivariate Analysis (ANOVA) and the Tukey's Test. The results show that most of the companies were identified as analyzers and prospectors, respectively. It was verified that the strategies have a significant relationship with the indicators of Net Asset Value, Return on Shareholders' Equity, Return on Asset and Participation of Third Party Capital, in which the prospective strategy presented better results than the others. Thus, it was found that most companies adopted the analytical strategy, however the organizations that obtained the best results were the prospectors.
\end{abstract}

Keywords: Initial Public Offering (IPO); Organizational Strategies; Miles and Snow (1978); Economic-financial performance.

Esta obra está licenciada sob uma Licença Creative Commons Attribution 3.0.

\section{Introdução}

O mercado de capitais representa um meio de prover as empresas recursos financeiros necessários para o seu crescimento e competitividade (STEFFEN; ZANINI, 2012). Nesse mercado, após a realização de abertura de capital perante a Comissão de Valores Mobiliários (CVM) e o cumprimento das demais exigências legais, as sociedades anônimas poderão realizar, através de um intermediário financeiro, a primeira oferta pública de ações, denomina Initial Public Offering (IPO), em português, Oferta Pública Inicial (BM\&FBOVESPA, 2011; LEONI et al., 2014; SILVA; FAMÁ, 2010). 
A abertura de capital constitui um meio de se obter recursos permanentes para o financiamento de novos projetos de investimento, o crescimento e a modernização das atividades, além de favorecer o processo de reestruturação de capital (BOMFIM; SANTOS; PIMENTA JÚNIOR, 2006). A IPO é o acontecimento que marca a primeira venda de ações de uma empresa e, após isso, o início de negociação dessas ações em bolsa de valores (BM\&FBOVESPA, 2011). Fatores como as condições de mercado e as características das empresas são determinantes para o sucesso ou fracasso desse processo (SATURNINO et al., 2012).

Após a realização da abertura de capital e, consequentemente, da IPO, as empresas passam a ter mais obrigações, entre elas o fornecimento de informações mais detalhadas sobre seu desempenho ao mercado, possibilitando que os investidores analisem seus resultados. Desse modo, devem procurar alternativas que proporcionem melhores resultados e, consequentemente, retorno para os acionistas (BOMFIM; SANTOS; PIMENTA JÚNIOR, 2006).

É importante considerar que o crescimento e a sobrevivência das empresas não dependem somente da arrecadação de recursos. Dependem, sobretudo, da adaptação estratégica dessas organizações ao ambiente em que estão inseridas, visto que uma melhor adaptação estratégica desencadeará melhores resultados, aumento da eficiência e a otimização dos recursos da organização, refletindo, desse modo, no seu desempenho, sucesso e sustentabilidade (SOMAVILLA; MACHADO; SEHNEM, 2013). Nesse interim, o comportamento estratégico varia de acordo com a percepção que os administradores têm do ambiente organizacional e como reagem diante dela para que a organização mantenha-se competitiva (ROSSETO, 2001).

Miles e Snow (1978) desenvolveram a conceituação de quatro tipologias estratégicas utilizadas pelas organizações, que são: defensora, prospectora, analisadora e reatora. As organizações defensoras são aquelas que priorizam a eficiência e procuram garantir estabilidade no seu domínio produto-mercado, focando no preço e na qualidade dos produtos atuais. As prospectoras, pelo contrário, buscam novos mercados e investem na inovação de produtos e processos, por isso tendem a ser precursoras de novidades. As analisadoras, por sua vez, são uma mistura entre as defensoras e as prospectoras, pois além de procurarem manter estabilidade de produtos e clientes, procuram explorar novos produtos e mercados. Por fim, as reatora são as organizações que agem por impulso quando pressionada por eventos ambientais (GIMENEZ et al., 1999; SOMAVILLA; MACHADO; SEHNEM, 2013; MILES et al., 1978).

Sabendo que o comportamento estratégico está atrelado à percepção que os administradores têm do ambiente organizacional e como respondem a esse ambiente, e que ao abrirem o capital, as empresas procuram cada vez mais meios que proporcionem melhores resultados e, em consequência, retorno para os acionistas, o presente estudo norteia-se pelo seguinte problema de pesquisa: Qual a influência das estratégias organizacionais, com base na tipologia de Miles e Snow (1978), no desempenho econômico-financeiro das empresas que realizaram IPO (Initial Public Offerings) no período de 2008 a 2012? Desta forma, o estudo objetivou analisar a influência das estratégias organizacionais, com base na tipologia de Miles e Snow (1978), no desempenho econômicofinanceiro das empresas que realizaram IPO (Initial Public Offerings) no período de 2008 a 2012.

A realização deste estudo justifica-se por oferecer explicações sobre como as empresas, ao abriram o seu capital, se comportam em seu ambiente, respondem aos problemas do ciclo adaptativo e buscam soluções no momento inicial do acesso ao mercado de capitais. Além disso, verifica a influência da estratégia organizacional adotada no desempenho econômico-financeiro, contribuindo com discussões afins. De forma complementar, serve como base para comparação com as empresas que atuam há mais tempo no mercado, como as cinquentenárias, que de acordo com estudo recente de Silva et al. (2015), em sua maioria, optam por a tipologia estratégica prospectora.

\section{Referencial Teórico}

O referencial teórico está subdivido em três partes. A primeira parte aborda o processo de abertura de capital e a Initial Public Offering (IPO). Na segunda parte, faz-se alusão ao tema estratégia organizacional, apresentando conceitos, bem como a conceituação das tipologias estratégicas de Miles e Snow (1978). Por fim, a terceira parte descreve a relação existente entre a estratégia e o desempenho organizacional, além de mencionar estudos correlatos.

\subsection{Abertura de capital e Initial Public Offering (IPO)}

Steffen e Zanini (2012) abordam que o mercado de capitais é um dos meios que as empresas utilizam para conseguirem financiamento externo, necessário para o seu crescimento e para que se mantenham competitivas. Nesse mercado, após a transformação em sociedade anônima, a realização de abertura de capital perante a Comissão de Valores Mobiliários (CVM), órgão que regula e fiscaliza o mercado de capitais no Brasil, e o requerimento de listagem em uma bolsa de valores, a empresa está autorizada a realizar a primeira oferta pública de ações, denomina Initial Public Offering (IPO), em português, Oferta Pública Inicial, devendo todas as emissões ambicionadas serem aprovadas e registradas pela CVM e serem realizadas por meio de um intermediário financeiro (BM\&FBOVESPA, 2011; LEONI et al., 2014; SILVA; FAMÁ, 2010). 
http://www.revista.ufpe.br/gestaoorg

A abertura de capital é uma das decisões mais importantes para qualquer empresa, já que consiste em uma decisão estratégica que causa alterações definitivas na gestão, controles internos e transparência das empresas (BM\&FBOVESPA, 2011). Bomfim, Santos e Pimenta Júnior (2006) citam que esse processo constitui um meio para acesso ao mercado capaz de fornecer recursos permanentes que possibilitem o financiamento de novos projetos de investimento, o crescimento e a modernização das atividades, além de favorecer o processo de reestruturação de capital.

Segundo Saturnino et al. (2012), a IPO é um meio de captação de recursos de longo prazo pelas empresas, com objetivo de pagar seus compromissos no curto prazo, bem como subsidiar seus investimentos e capital de giro. De acordo com os autores, o sucesso ou insucesso dessa alternativa é influenciado pelas condições do mercado ou por características atreladas às empresas que lançam títulos na bolsa de valores.

A motivação de lançar ações no mercado público varia de empresa para empresa, no entanto, pode-se observar que o crescimento ou a necessidade de crescimento exerce papel de fundamental importância na decisão das empresas que entram no mercado de ações (SAMPAIO, 2011). Corroborando com essa ideia, o estudo de Bomfim, Santos e Pimenta Júnior (2006) identificou que os principais fatores motivadores para a abertura de capital de algumas empresas durante os exercícios de 2004 e 2005 foram a obtenção de recursos para financiar seus projetos de expansão além da adoção de estratégias de valorização e crescimento. O estudo de Steffen e Zanini (2012), por sua vez, investigou a percepção dos executivos financeiros sobre a IPO no Brasil e revela que a obtenção de recursos adicionais para crescimento no curto e longo prazo, a redução de custo de capital, promoção de estrutura ótima de capital e a melhoria na percepção do mercado sobre a companhia são considerados benefícios de realizar IPO.

Para realizar a abertura de capital é imprescindível que a empresa esteja preparada, já que deverá atender as expectativas dos acionistas e do mercado, bem como exigências permanentes relacionadas a aspectos regulatórios, eficiência operacional, gestão de risco, emissão de relatórios periódicos e relação com investidores. Empresas que tenham crescimento sólido e projetos bem fundamentados são mais atraentes para investidores potenciais (BM\&FBOVESPA, 2011).

Ao abrirem o capital, as empresas são obrigadas a fornecerem informações mais detalhadas sobre seu desempenho ao mercado. Desse modo, os investidores passam a analisar seus resultados, apontando falhas e acertos e oferecendo ideias para melhoria de desempenho. Assim, as empresas procuram cada vez mais meios que proporcionem melhores resultados e, consequentemente, retorno para os acionistas (BOMFIM; SANTOS; PIMENTA JÚNIOR, 2006).

\subsection{Estratégias organizacionais}

Colauto e Beuren (2006) aludem que a escolha da estratégia empresarial é norteada pelas especificidades do mercado e do ambiente econômico e que esta corresponde a um referencial que guiará as ações praticadas com a finalidade de criar vantagem competitiva em relação à concorrência e satisfazer as necessidades dos consumidores. Em relação a isso, Thompson Jr., Strickland III e Gamble (2008, p. 04) diz que a estratégia empresarial “ (...) consiste nos passos competitivos e nas abordagens administrativas que os gerentes utilizam para o crescimento do negócio, para atrair e satisfazer aos clientes, para competir de modo bem-sucedido e alcançar os níveis almejados de desempenho organizacional".

A estratégia utilizada pela empresa varia de acordo com a percepção que os administradores têm do ambiente organizacional e como reagem diante dele para que a empresa se mantenha competitiva (ROSSETO, 2001). Considerando que as organizações são diversificadas, mutáveis e complexas, elas tendem a adotar estratégias variadas (SOMAVILLA; MACHADO; SEHNEM, 2013). A adoção de uma estratégia organizacional é de grande importância para a empresa, pois esta dificilmente conseguirá atender a variadas demandas dos variados segmentos do mercado ao mesmo tempo. Além disso, dificilmente conseguirá de forma imediata mudar drasticamente as condições de atendimento ou mudar de um segmento de mercado para o outro (OLIVEIRA, 2004).

No que diz respeito à adaptação estratégica, Miles e Snow (1978) desenvolveram um modelo geral do processo adaptativo denominado ciclo adaptativo. Para os autores, esse ciclo compreende três problemas de adaptação organizacional, que são: o problema empreendedor, o problema de engenharia e o problema administrativo. $\mathrm{O}$ problema empreendedor refere-se à definição de um domínio organizacional, que corresponde à escolha de um produto ou serviço específico para determinado mercado-alvo ou segmento de mercado. O problema de engenharia, por sua vez, concerne à escolha de uma tecnologia apropriada para operacionalizar o produto ou serviço escolhido no problema empreendedor. Por fim, o problema administrativo corresponde ao controle da organização em busca da racionalização e estabilização das atividades que solucionaram com êxito os dois problemas anteriores (PEINADO; FERNANDES, 2012; MILLES et al., 1978). 
Ainda de acordo com Miles e Snow (1978), para responder os três problemas do ciclo adaptativo impostos pelo ambiente, as empresas podem utilizar quatro tipologias estratégicas, que são: defensora, prospectora, analisadora e reatora.

Empresas defensoras buscam garantir uma posição segura e estável, e fazem isso por meio da produção de apenas um conjunto de produtos destinados a atender um pequeno segmento do mercado. Dentro desse ambiente, esforçam-se de forma agressiva para impedir a entrada de concorrentes em seu território, por isso enfatizam a eficiência, ofertando preços competitivos ou produtos de alta qualidade. (MILLES et al., 1978; PEINADO; FERNANDES, 2012; SOARES; TEIXEIRA; PELISSARI, 2011).

Organizações prospectoras, por sua vez, são inovadoras e buscam sempre encontrar e explorar novas oportunidades de produtos e mercados. Possuem domínio amplo e em constante desenvolvimento e, geralmente, são os criadores de mudanças em seus setores de atuação (MILLES et al., 1978; PEINADO; FERNANDES, 2012; SOARES; TEIXEIRA; PELISSARI, 2011).

Empresas analisadoras são uma combinação da estratégia defensora e prospectora, pois tentam minimizar o risco e maximizar a oportunidade de lucro, combinando os pontos fortes dos defensores e prospectores. Exploram novos produtos e mercados ao mesmo tempo em que procuram manter um domínio estável de produtos e clientes.

Por fim, os reatores não se configuram como uma tipologia estratégica pura, mas residual. Respondem ao ambiente de forma inconsistente e instável $\mathrm{e}$, devido a falta de uma orientação consistente, reagem às pressões do ambiente apenas quando forçados. Assim, apresentam desempenho inferior em relação às três tipologias já mencionadas (MILLES et al., 1978; PEINADO; FERNANDES, 2012; SOARES; TEIXEIRA; PELISSARI, 2011).

\subsection{Estratégias, desempenho organizacional e estudos correlatos}

O desempenho de uma organização diz respeito aos resultados por ela obtidos em determinado período, podendo ser avaliado por parâmetros quantificáveis denominados indicadores (FERNANDES; FLEURY; MILLS, 2006; BRANDÃO; BORGES-ANDRADE; GUIMARÃES, 2012). Para Ribeiro, Macedo e Marques (2012), o desempenho tem relação com as estratégias e metas definidas pela organização e como elas norteiam esforços para garantir o sucesso organizacional.

A esse respeito, Lavieri e Carneiro da Cunha (2009) mencionam que a avaliação de desempenho organizacional é importante, pois possibilita compreender se as ações e resultados obtidos estão em sintonia com a estratégia estabelecida. Para Gulini (2005), entre os modelos de avaliação de desempenho que ganham destaque, estão os indicadores econômico-financeiros. Dal Magro, Domenico e Hein (2014) abordam que a avaliação financeira fornece aos diversos usuários uma visão corrente e retrospectiva dos aspectos econômico-financeiros das empresas. Nesse sentido, as demonstrações financeiras, bem como os índices que podem ser extraídos dos valores nelas explícitos, são importante fonte de informação sobre a situação econômica, financeira e patrimonial de uma organização e permitem subsidiar as decisões de investidores.

É possível observar a estreita relação entre a estratégia adotada pela empresa e os resultados obtidos. No que concerne às tipologias estratégicas de Miles e Snow (1978), alguns estudos nacionais e internacionais investigaram a relação entre as estratégias organizacionais e o desempenho obtido por variados grupos de empresas, demonstrando resultados distintos.

Jennings, Rajaratnam e Lawrence (2003) investigaram a relação entre a tipologia estratégia e o desempenho em empresas de serviços norte-americanas. Considerando medidas de desempenho como a taxa de crescimento dos lucros, taxa de crescimento de vendas, retorno sobre o investimento e retorno sobre a venda, os autores verificaram que o desempenho geral das empresas reatoras foi significativamente menor que o desempenho das empresas prospectoras, analisadoras e defensoras. Por outro lado, observaram que não houve diferença significativa no desempenho entre essas três tipologias.

Avci, Madanoglu e Okumus (2011) investigaram se empresas turcas de turismo adotavam as estratégias de Miles e Snow (1978) e se apresentavam desempenho financeiro ou não financeiro diferenciado de acordo com cada estratégia. Os resultados apontam que a maioria das empresas foi caracterizada como analisadora e o desempenho superior concentrou-se nas empresas prospectoras. Em muitos casos, os prospectores tiveram desempenho superior aos defensores, no entanto, as empresas prospectoras e analisadoras apresentaram desempenho financeiro e não financeiro parecido.

Koseoglu et al. (2013) examinaram a relação entre estratégia de negócios, incerteza ambiental e desempenho em empresas turcas do setor hoteleiro, chegando a conclusão de que as estratégias organizacionais dos hotéis turcos foram influenciados pela incerteza ambiental, no entanto essa incerteza não teve relação significante com o 
http://www.revista.ufpe.br/gestaoorg

desempenho financeiro e não financeiro. $\mathrm{O}$ estudo revela ainda que empresas prospectoras e defensoras obtiveram melhores resultados no que diz respeito ao desempenho financeiro e não financeiro.

Pletsch et al. (2015) verificaram a influência das estratégias competitivas, com base nas tipologias de Miles e Snow (1978), no desempenho econômico-financeiro de empresas brasileiras do setor não cíclico, listadas na BM\&FBOVESPA, no período de 2013. Os resultados do estudo demonstram que a maioria das empresas analisadas adota a estratégia prospectora, seguida da defensora, analisadora e reatora, respectivamente. Os achados também evidenciam que as empresas que adotam a estratégia prospectora tendem a obter maior rentabilidade sobre o patrimônio líquido, enquanto as que adotam a estratégia analisadora tendem a apresentar melhor indicador de liquidez corrente. Em contrapartida, as empresas com estratégia reatora tendem a apresentar desempenho inferior em relação aos mencionados índices.

Silva et al. (2015) verificaram a influência das estratégias organizacionais, de acordo com a tipologias de Miles e Snow (1978), no desempenho econômico-financeiro de empresas cinquentenárias brasileiras. Os resultados demonstram que a maioria das empresas cinquentenárias analisadas classifica-se como prospectora, analisadora, reatora e defensora, respectivamente. $\mathrm{O}$ estudo revela ainda que as empresas cinquentenárias que adotam as estratégias prospectoras e reatoras obtiveram as maiores médias no indicador Retorno Sobre o Patrimônio Líquido, enquanto as estratégias defensora e analisadora tiveram menores médias.

\section{Procedimentos Metodológicos}

Quanto ao objetivo, este estudo é do tipo exploratório, pois busca aprofundar o tema estratégias organizacionais e a sua relação com o desempenho econômico-financeiro de empresas que realizaram IPO. Quanto à tipologia, configura-se como pesquisa bibliográfica e documental, pois faz uso de materiais já elaborados para reunir conhecimento e dar embasamento ao tema pesquisado, além de fazer uso de materiais que ainda não foram analisados com maior profundidade, que são relatórios da administração das empresas que realizaram IPO de 2008 a 2012. Além disso, foram coletados os dados econômico-financeiros na base Economática ${ }^{\circledR}$, com a finalidade de verificar a influência das estratégias adotadas pelas organizações sobre o seu desempenho econômico-financeiro. O presente estudo faz uso de uma abordagem quantitativa, pois foram utilizados procedimentos estatísticos para responder o problema de pesquisa.

O primeiro passo para a realização desta pesquisa foi a consulta das empresas que realizaram IPO no site da BM\&FBovespa. Ressalta-se que se optou pelo período de 2008 a 2012 com o intuito de obter os dados necessários para a pesquisa, especialmente os dados econômico-financeiros dos quatro anos após a realização da IPO.

Observou-se que no período em questão 35 empresas realizaram IPO, mas para fins de análise foram excluídas 02 organizações financeiras e 08 empresas que não se encontravam listadas na BM\&FBovespa, o que dificultou a obtenção de dados para a pesquisa. Por fim, obteve-se a amostra da pesquisa, que é composta por 25 empresas, conforme Quadro 1:

Quadro 1: Amostra final do estudo, em ordem alfabética

\begin{tabular}{|l|l|}
\hline \multicolumn{2}{|c|}{ Empresa que realizaram IPO de 2008 a 2012 } \\
\hline Aliansce Shopping Centers S.A. & Multiplus S.A. \\
\hline Arezzo Indústria e Comércio S.A. & Nutriplant Indústria e Comércio S.A. \\
\hline BR Properties S.A. & OSX Brasil S.A. \\
\hline Brasil Insurance Participações e Administração S.A. & QGEP Participações S.A. \\
\hline Brazil Pharma S.A. & Qualicorp S.A. \\
\hline CETIP S.A. - Balcão Organizado de Ativos e Derivativos & Raia S.A. \\
\hline Cia Locação das Américas & Renova Energia S.A. \\
\hline Direcional Engenharia S.A. & Restoque Comércio e Confecções de Roupas S.A. \\
\hline Ecorodovias Infraestrutura e Logística S.A. & Sonae Sierra Brasil S.A. \\
\hline Fleury S.A. & T4F Entretenimento S.A. \\
\hline Hypermarcas S.A. & Technos S.A. \\
\hline Magazine Luiza S.A. & Unicasa Indústria de Móveis S.A. \\
\hline Mills Estruturas e Serviços de Engenharia S.A. & \\
\hline
\end{tabular}

Fonte: Adaptado de BM\&FBOVESPA (2016).

Considerando as 35 empresas, observou-se que os anos que mais tiveram realização de IPO foram 2010 e 2011, pois em cada ano 11 empresas fizeram oferta inicial de ações. Por outro lado, os anos que menos tiveram realização de IPO foram 2012, 2008 e 2009, com 3, 4 e 6 empresas, respectivamente. Verificou-se também que no período pesquisado houve uma diversificação muito grande da classificação setorial das empresas ofertantes 
de ações, sendo que os segmentos que mais realizaram ofertas foram o de exploração de imóveis e o de exploração e/ou refino, com 3 empresas cada.

Em seguida, realizou-se a pesquisa do primeiro relatório da administração disponibilizado por cada empresa pesquisada após a realização da IPO, através do site da BM\&FBovespa. Depois de obter os relatórios, realizouse a leitura desses documentos com a finalidade de extrair inferências que caracterizaram as estratégias adotadas pelas organizações em prospectora, defensora, analisadora e reatora, conforme Miles e Snow (1978).

A tipificação das empresas foi realizada do mesmo modo que Pletsch et al. (2015) e Silva et al. (2015), que buscaram identificar a tipologia estratégica utilizada pelas empresas por meio de afirmativas descritivas contidas no relatório de administração. Assim, realizou-se a leitura do relatório da administração das 25 empresas que pertencem à amostra com a finalidade de encontrar afirmativas que permitissem tipificar a estratégia adotada por cada empresa, conforme Miles e Snow (1978). Segue exemplo da tipologia prospectora: "Continuamos a nossa liderança em inovação. Em 2010, lançamos novos produtos em todas as nossas divisões.".

Após a observação das estratégias competitivas, os dados foram organizados em planilha eletrônica, na qual foram categorizadas as estratégias, com a finalidade da aplicação da análise multivariada de dados (ANOVA), da seguinte forma:

Quadro 2: Categorização das estratégias organizacionais de acordo com Miles e Snow (1978)

\begin{tabular}{|l|ll|}
\hline \multicolumn{1}{|c|}{ Estratégias } & \multicolumn{1}{c|}{ Categorização } \\
\hline Não identificada & 1 & \\
Prospectora & 2 & \\
Defensora & 3 & \\
Analisadora & 4 & \\
Reatora & 5 & \\
\end{tabular}

Fonte: Dados da pesquisa.

Nesta pesquisa foram utilizados índices de estrutura de capital (Participação de Capitais de Terceiros e Imobilização do Patrimônio Líquido), índices de liquidez ou solvência (Liquidez Geral, Liquidez Corrente e Liquidez Seca) e índices de rentabilidade (Rentabilidade do Ativo e Rentabilidade do Patrimônio Líquido), índices esses utilizados nos estudos de Pletsch et al. (2015) e Silva et al. (2015). Assim, os indicadores utilizados neste estudo são apresentados no Quadro 3.

Quadro 3: Índices econômico-financeiros

\begin{tabular}{|c|c|}
\hline Indicador & Fórmula \\
\hline \multicolumn{2}{|c|}{ Estrutura de Capital } \\
\hline Participação de Capital de Terceiros (PARTCTERC) & $\begin{array}{l}\text { Passivo Circulante+Passivo Não-Circulante } \\
\text { Patrimônio Líquido }\end{array}$ \\
\hline $\begin{array}{l}\text { Imobilização do Patrimônio Líquido } \\
\text { (IMOBPL) }\end{array}$ & $\begin{array}{l}\text { Ativo Não Circulante - Realiz. a Longo Prazo } \\
\text { Patrimônio Líquido }\end{array}$ \\
\hline \multicolumn{2}{|c|}{ Liquidez } \\
\hline Liquidez Geral (LIQGER) & $\begin{array}{l}\text { Ativo Circulante+Ativo Realiz. a Longo Prazo } \\
\text { Passivo Circulante+Passivo Exigível a Longo Prazo }\end{array}$ \\
\hline Liquidez Corrente (LIQCOR) & $\begin{array}{l}\text { Ativo Circulante } \\
\text { Passivo circulante }\end{array}$ \\
\hline Liquidez Seca (LIQSEC) & $\begin{array}{l}\text { Ativo Circ. - Estoques-Desp. Antecipadas- } \\
\text { Tributos a Recuperar } \\
\text { Passivo Circulante }\end{array}$ \\
\hline \multicolumn{2}{|c|}{ Rentabilidade } \\
\hline Rentabilidade do Ativo (ROA) & $\begin{array}{l}\text { Lucro Líquido } \\
\text { Ativo total }\end{array}$ \\
\hline Rentabilidade do Patrimônio Líquido (ROE) & $\begin{array}{l}\text { Lucro Líquido } \\
\text { Patrimônio Líquido }\end{array}$ \\
\hline
\end{tabular}

Fonte: Adaptado de Ribeiro (2014), Pletsch et al. (2015) e Silva et al. (2015).

Cabe salientar que nos índices Imobilização do Patrimônio Líquido e Liquidez Geral, foram utilizadas fórmulas diferentes das utilizadas por Pletsch et al. (2015) e Silva et al. (2015), em decorrência das alterações na estrutura do balanço patrimonial promovidas pela Lei 11.941/2009. Desse modo, optou-se por utilizar as fórmulas descritas por Ribeiro (2014).

Foram coletados os dados necessários para calcular os indicadores econômico-financeiros, contidos nas 
http://www.revista.ufpe.br/gestaoorg

demonstrações contábeis divulgadas pelas empresas pesquisadas, referentes aos quatro primeiros exercícios financeiros após a realização do IPO. Por exemplo, para as empresas que realizaram IPO em 2008, foram utilizados os dados de 2008, 2009, 2010 e 2011, para as empresas que realizaram IPO em 2009, fez-se o uso dos dados 2009, 2010, 2011 e 2012, e assim por diante.

Dessa forma, os indicadores expostos no Quadro 3 foram utilizados como variáveis dependentes na análise multivariada (ANOVA) do presente estudo e as estratégias organizacionais devidamente tabuladas de acordo com a sua categorização foram utilizadas com variáveis independentes.

\section{Análise Dos Resultados}

Neste capítulo são apresentados os resultados da pesquisa. Apresentam-se nos Quadros 4, 5 e 6 as inferências retiradas dos relatórios de administração que permitiram a tipificação das estratégias organizacionais. A seguir, são expostas algumas inferências que determinaram a categorização da tipologia prospectora.

Quadro 4: Observações de determinação da categorização da tipologia prospectora

\begin{tabular}{|c|c|c|}
\hline Empresa & Observação no relatório da administração & Base teórica \\
\hline 1 & $\begin{array}{l}\text { "A combinação de disponibilidade de capital, } \\
\text { oportunidades de mercado e o espírito empreendedor } \\
\text { (...) nos levou a dobrarmos o número de unidades de } \\
20 \text { para } 40 \text { no ano de } 2010 \text {, ou seja, antecipamos em } \\
\text { um ano o nosso plano de expansão geográfica. } \\
\text { Planejamos abrir nove novas unidades em } 2011 \text {, dando } \\
\text { continuidade ao nosso plano de expansão geográfica } \\
\text { que é estratégico para o crescimento (...)". } \\
\text { "Continuamos a nossa liderança em inovação. Em } \\
\text { 2010, lançamos novos produtos em todas as nossas } \\
\text { divisões." }\end{array}$ & $\begin{array}{l}\text { Miles e Snow (1978) descrevem } \\
\text { os prospectores estão envolvidos } \\
\text { em um ambiente mais dinâmico, } \\
\text { buscando constantemente inovar } \\
\text { no desenvolvimento de novos } \\
\text { produtos e oportunidades de } \\
\text { mercado. }\end{array}$ \\
\hline 2 & $\begin{array}{l}\text { "Contínuo investimento em marketing e } \\
\text { desenvolvimento de produtos - pilares estratégicos (...) } \\
\text { impactou positivamente os resultados da rede." } \\
\text { "Sua linhas de produtos destacam-se pela constante } \\
\text { inovação, design, conforto e excelente relação custo } \\
\text { benefício." } \\
\text { "É referência no lançamento de tendências no Brasil, } \\
\text { lança de sete a nove coleções anuais(...)". }\end{array}$ & $\begin{array}{l}\text { Miles e Snow (1978) mencionam } \\
\text { que os prospectores são } \\
\text { inovadores no desenvolvimento de } \\
\text { produtos e mercado. Mencionam } \\
\text { ainda que os prospectores são } \\
\text { frequentemente os criadores de } \\
\text { mudança em seus respectivos } \\
\text { setores e essa mudança é uma das } \\
\text { principais ferramentas utilizadas } \\
\text { para ganhar vantagem sobre os } \\
\text { concorrentes. }\end{array}$ \\
\hline
\end{tabular}

Fonte: Dados da pesquisa.

Desarbo (2005) menciona que as empresas prospectoras são aquelas tecnologicamente inovadoras, que buscam constantemente lançar novos produtos e identificar novas oportunidades de mercado. Peinado e Fernandes (2012) afirmam que empresas prospectoras frequentemente provocam mudanças e incertezas de mercado para seus concorrentes.

No Quadro 5 são apresentadas as inferências observadas nos relatórios de administração que permitiram a categorização das empresas na tipologia estratégica defensora.

Quadro 5: Observações de determinação da categorização da tipologia defensora

\begin{tabular}{|c|c|c|}
\hline Empresa & Observação no relatório da administração & Base teórica \\
\hline 1 & $\begin{array}{l}\text { "Foram feitos investimentos para ganhos de } \\
\text { produtividade em seus processos e ganhos de qualidade } \\
\text { em seus produtos. Atualmente a empresa tem } \\
\text { capacidade para produzir cerca de } 55 \text { mil toneladas (...) } \\
\text { por ano, em dois turnos de produção." } \\
\text { "(...) um esforço em buscar clientes que representem } \\
\text { um menor risco de crédito, dado o risco associado ao } \\
\text { financiamento de longo prazo das vendas. Tais clientes } \\
\text { são, em geral, de maior porte, demandando um maior } \\
\text { volume de insumos, mas também um preço } \\
\text { diferenciado." }\end{array}$ & $\begin{array}{l}\text { Miles e Snow (1978) salientam } \\
\text { que os defensores são } \\
\text { caracterizados pela constante } \\
\text { eficiência na produtividade do } \\
\text { portfólio de produtos já existentes. } \\
\text { Em seu domínio estável de } \\
\text { produto e mercado, investem em } \\
\text { ações como } \\
\text { preços competitivos ou produtos } \\
\text { de alta qualidade. }\end{array}$ \\
\hline
\end{tabular}


http://www.revista.ufpe.br/gestaoorg

\begin{tabular}{|l|l|l|}
\hline & & \\
\hline 2 & "O foco e a experiência (...) em grandes projetos & Miles e Snow (1978) definem que \\
populares e a demanda específica das regiões que \\
elegemos como prioridade de atuação nos colocam em \\
situação privilegiada." \\
"A atuação (...) é focada na construção de \\
empreendimentos populares e concentrada nus regióes manter um \\
domínio estável, produzindo \\
apenas um conjunto de produtos \\
direcionados a um segmento de \\
mercado potencial. Dentro desse \\
Norte e Centro-Oeste. Nessas regiões, a Companhia \\
enfrenta menor competição uma vez que os \\
concorrentes são players locais, que não contam com \\
estrutura de capital competitiva e cujos produtos têm \\
agressiva para impedir a entrada \\
pouca diferenciação." concorrentes em seus \\
territórios.
\end{tabular}

Fonte: Dados da pesquisa.

Jennings, Rajaratnam e Lawrence (2003) mencionam que os defensores normalmente oferecem os seus produtos ou serviços a um segmento definido do mercado total. Nesse mercado alvo, se esforçam para construir clientes satisfeitos, oferecendo produtos e serviços de maior qualidade e preços competitivos. Rosseto (2001) menciona que essas empresas dedicam atenção à melhoria da eficiência das operações vigentes.

Por fim, no Quadro 6, são exibidas as inferências observadas nos relatórios de administração que indicaram a categorização das empresas na tipologia estratégica analisadora.

Quadro 6: Observações de determinação da categorização da tipologia analisadora

\begin{tabular}{|c|c|c|}
\hline Empresa & Observação no relatório da administração & Base teórica \\
\hline 1 & $\begin{array}{l}\text { “(...) inaugurou } 124 \text { lojas em 2011, passando de } 604 \\
\text { em } 2010 \text { para } 728 \text { lojas em dezembro de } 2011 . " \\
\text { “(...) é acertada a nossa estratégia de crescer e } \\
\text { consolidar, para depois crescer novamente. E este ano } \\
\text { de } 2012 \text { será de consolidação do crescimento sólido } \\
\text { que estamos construindo há muito tempo." } \\
\text { "O nosso foco em } 2012 \text { é consolidar e integrar } \\
\text { completamente as redes recém adquiridas, racionalizar } \\
\text { custos e despesas, e aumentar a produtividade da } \\
\text { Companhia. A maturação da expansão que vivemos em } \\
2011 \text { é o nosso compromisso com os investidores." }\end{array}$ & $\begin{array}{l}\text { Miles e Snow (1978) aludem que } \\
\text { os analisadores diferenciam a } \\
\text { estrutura e os processos da } \\
\text { organização para acomodar áreas } \\
\text { estáveis e dinâmicas de } \\
\text { funcionamento. Desse modo, os } \\
\text { analisadores combinam esforços } \\
\text { de aspectos dos defensores, como } \\
\text { a consolidação de mercado com } \\
\text { eficiência, e dos prospectores, } \\
\text { como a ampliação de serviços e } \\
\text { ofertas em novos mercados. }\end{array}$ \\
\hline 2 & $\begin{array}{l}\text { "Concentramos nossas estratégias na expansão da base } \\
\text { de clientes através de entidades profissionais de classe, } \\
\text { envidando os nossos melhores esforços não só para } \\
\text { aumentar a quantidade de entidades profissionais de } \\
\text { classe parceiras, como também para incrementar a } \\
\text { participação e penetração dentro das entidades atuais, } \\
\text { promovendo assim o crescimento orgânico da nossa } \\
\text { base de clientes, além de continuar expandindo as } \\
\text { nossas atividades para outras regiões ainda não } \\
\text { exploradas por nós." } \\
\text { "Para } 2012 \text { manteremos o foco na estratégia de } \\
\text { crescimento, consolidação de mercado e investimentos } \\
\text { em novas oportunidades." }\end{array}$ & $\begin{array}{l}\text { Miles e Snow (1978) afirmam que } \\
\text { os analisadores são uma } \\
\text { combinação dos prospectores e } \\
\text { defensores. Os analisadores } \\
\text { tentam minimizar o risco e } \\
\text { maximizar a oportunidade de } \\
\text { lucro, combinando em um único } \\
\text { sistema os pontos fortes dos } \\
\text { prospectores e defensores. Desse } \\
\text { modo, buscam o equilíbrio. }\end{array}$ \\
\hline
\end{tabular}

Fonte: Dados da pesquisa.

Soares, Teixeira e Pelissari (2011) argumenta que os analisadores são uma mistura dos prospectores e defensores, pois procuram manter um domínio estável de produtos e clientes, mas ao mesmo tempo se envolvem na exploração de novos produtos e mercados. Procuram minimizar o risco sem abrir mão de oportunidades.

Neste estudo, não foram encontradas empresas caracterizadas como reatoras, que, de acordo com Peinado e Fernandes (2012), trata-se de uma forma de não estratégia, pois as empresas percebem as mudanças do ciclo adaptativo, mas não conseguem responder efetivamente a essas mudanças. Esse achado vai ao encontro do estudo de Avci, Madanoglu e Okumus (2011), que demonstra que com o passar do tempo o número de empresas caracterizadas como reatoras tende a diminuir.

Depois de demonstrar algumas inferências que indicaram a categorização das empresas ao iniciarem as 
http://www.revista.ufpe.br/gestaoorg negociações no mercado acionário entre as tipologias estratégicas, tem-se a análise descritiva dos dados, com a finalidade de demonstrar as estratégias de Miles e Snow (1978) observadas nas organizações que fazem parte da amostra, conforme Tabela 1.

Tabela 1: Frequências das estratégias organizacionais de Miles e Snow

\begin{tabular}{|c|c|c|}
\hline Estratégias & Quantidade & $\%$ \\
\hline Não identificada & 3 & 12,00 \\
\hline Analisadora & 12 & 48,00 \\
\hline Prospectora & 8 & 32,00 \\
\hline Defensora & 2 & 8,00 \\
\hline Reatora & 0 & 0,00 \\
\hline Total & 25 & 100,00 \\
\hline
\end{tabular}

Fonte: Dados da pesquisa.

Os resultados indicam que a maioria das empresas foram tipificadas como analisadoras, com $48 \%$ das observações. A segunda estratégia mais adotada foi a prospectora, com $32 \%$ dos casos. Por fim, a estratégia defensora foi observada em $8 \%$ da amostra. Cabe salientar que neste estudo não foram encontradas empresas caracterizadas como reatoras, conforme mencionado anteriormente. Destaca-se também que em $12 \%$ das empresas analisadas não foi possível identificar, nos relatórios da administração, a tipologia estratégica. Portanto, essas empresas foram excluídas da análise ANOVA e do teste Tukey.

Percebe-se que ao iniciarem as negociações no mercado acionário, a maior parte das empresas pesquisadas optou pela estratégia analisadora, pois combinam aspectos da defensora (consolidação do mercado com eficiência) e da prospectora (ampliação de serviços e oferta em novos mercados). No entanto, é importante observar que boa parte das empresas foi caracterizada como prospectora, buscando constantemente lançar novos produtos e identificar novas oportunidades de mercado, e a minoria foi caracterizada como defensora, que são aquelas que procuram manter uma posição estável no seu domínio produto-mercado (MILES et al., 1978).

Na Tabela 2, apresenta-se o resultado do teste da Análise Multivariada (ANOVA). Antes de realizar o teste ANOVA, efetuou-se o teste não paramétrico de Kolmgorov-Sminorv para verificar a normalidade dos dados, que demonstrou uma distribuição normal das variáveis a um nível de $5 \%$ (p-value $<0,05$ ).

Tabela 2: Resultado da ANOVA

\begin{tabular}{|c|c|c|c|c|c|c|}
\hline & & Soma dos Quadrados & DF & Quadrado Médio & $\mathbf{Z}$ & Sig. \\
\hline \multirow{3}{*}{ PARTCTERC } & Entre Grupos & 8,984 & 2 & 4,492 & \multirow{3}{*}{2,852} & \multirow{3}{*}{$0,065^{* *}$} \\
\hline & Nos grupos & 99,209 & 63 & 1,575 & & \\
\hline & Total & 108,193 & 65 & --------------- & & \\
\hline \multirow{3}{*}{ IMOBPL } & Entre Grupos & 1,622 & 2 & 0,811 & \multirow{3}{*}{3,484} & \multirow{3}{*}{$0,037^{*}$} \\
\hline & Nos grupos & 14,664 & 63 & 0,233 & & \\
\hline & Total & 16,286 & 65 & -------------- & & \\
\hline \multirow{3}{*}{ LIQGERAL } & Entre Grupos & 1677,625 & 2 & 83,881 & \multirow{3}{*}{1,300} & \multirow{3}{*}{0,280} \\
\hline & Nos grupos & 4064,504 & 63 & 64,515 & & \\
\hline & Total & 423,226 & 65 & ----- & & \\
\hline \multirow{3}{*}{ LIQCOR } & Entre Grupos & 89,161 & 2 & 44,580 & \multirow{3}{*}{1,784} & \multirow{3}{*}{0,176} \\
\hline & Nos grupos & 1574,530 & 63 & 24,993 & & \\
\hline & Total & 1663,691 & 65 & & & \\
\hline \multirow{3}{*}{ LIQSEC } & Entre Grupos & 88,636 & 2 & 44,318 & \multirow{3}{*}{1,729} & \multirow{3}{*}{0,186} \\
\hline & Nos grupos & 1614,572 & 63 & 25,628 & & \\
\hline & Total & 1703,208 & 65 & --------------- & & \\
\hline \multirow{3}{*}{ ROA } & Entre Grupos & 0,035 & 2 & 0,018 & \multirow{3}{*}{2,938} & \multirow{3}{*}{$0,060^{* *}$} \\
\hline & Nos grupos & 0,380 & 63 & 0,006 & & \\
\hline & Total & 0,415 & 65 & --------------- & & \\
\hline \multirow{3}{*}{ ROE } & Entre Grupos & 0,384 & 2 & 0,192 & \multirow{3}{*}{10,307} & \multirow{3}{*}{$0,000^{*}$} \\
\hline & Nos grupos & 1,173 & 63 & 0,019 & & \\
\hline & Total & 1,557 & 65 & ---- & & \\
\hline
\end{tabular}

Fonte: Dados da pesquisa.

*nível de significância de 5\%

**nível de significância de $10 \%$

$\mathrm{Na}$ Tabela 2, verifica-se que as estratégias organizacionais apresentaram relação significante, ao nível de 5\%, 
com os indicadores Imobilização do Patrimônio Líquido (IMOBPL) e Rentabilidade do Patrimônio Líquido (ROE). Verifica-se, também, que os indicadores Rentabilidade do Ativo (ROA) e Participação de Capitais de Terceiros (PARTCTERC) foram significantes ao nível de 10\%. Assim, na Tabela 3 são apresentados os resultados descritivos da ANOVA para as variáveis que apresentaram significância com as estratégias.

Tabela 3: Resultado descritivo da ANOVA

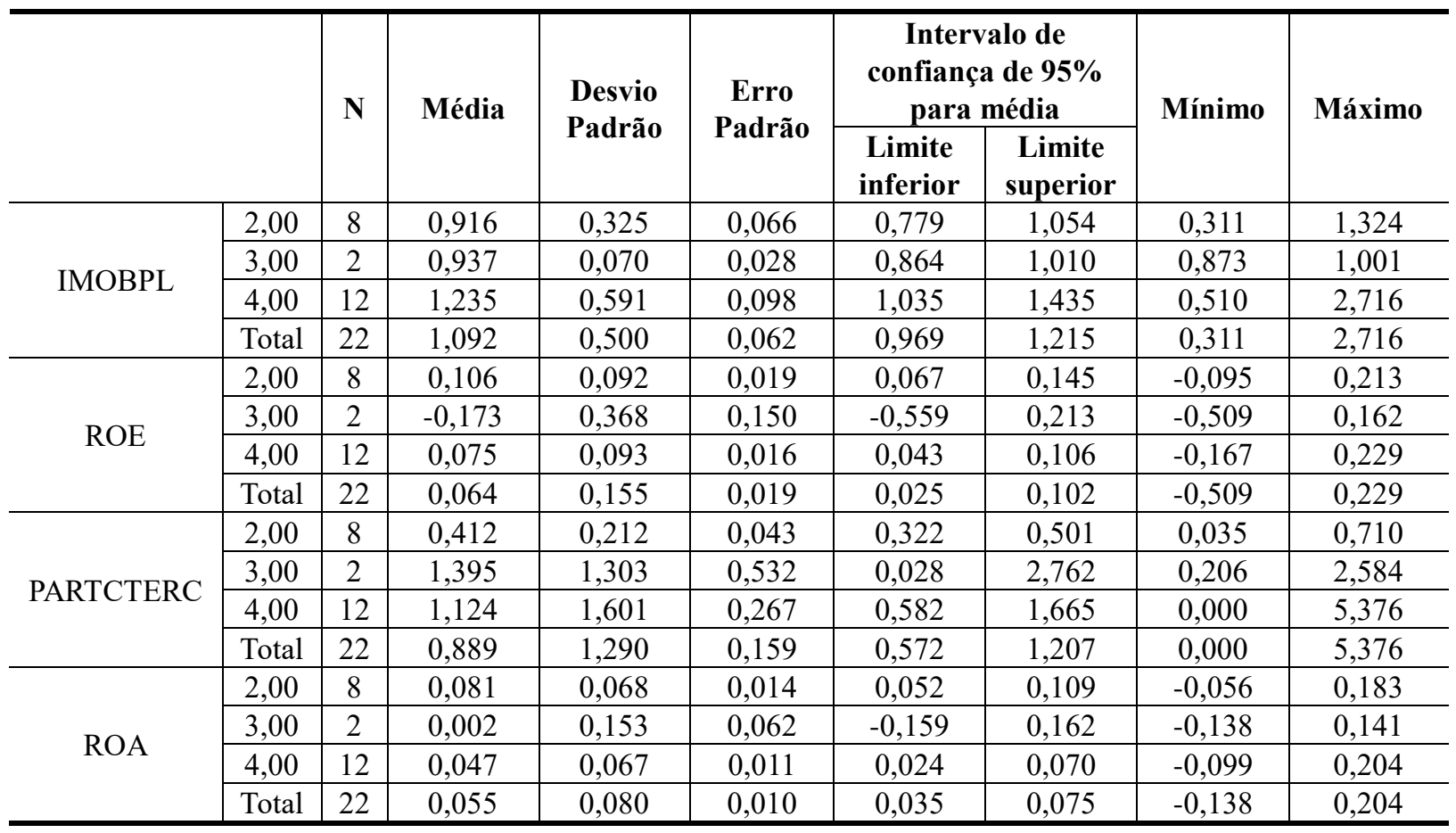

Fonte: Dados da pesquisa.

Quanto ao índice Imobilização do Patrimônio Líquido (IMOBPL), nota-se que a estratégia prospectora apresentou menor média, enquanto a estratégia analisadora apresentou a maior média. Esse indicador demonstra qual parcela do Patrimônio Líquido foi aplicada no Ativo Fixo e verifica a existência ou não de Capital Circulante Próprio. Assim, quanto menor esse índice, melhor para a empresa, visto que terá uma menor dependência no que concerne a Capital de Terceiros para financiar o Ativo Circulante mais o Realizável a Longo Prazo. Desse modo, pode-se afirmar que empresas prospectoras obtiveram melhor resultado nesse índice em relação às empresas analisadoras e defensoras.

No que concerne ao índice Rentabilidade do Patrimônio Líquido (ROE), observa-se que a estratégia prospectora apresentou maior média, enquanto a estratégia defensora apresentou menor média. Esse quociente revela qual foi a taxa de rentabilidade obtida pelo Capital Próprio investido na empresa, desse modo, quanto maior for esse indicador, melhor. Nota-se, portanto, que, mais uma vez, as empresas prospectoras apresentaram melhores resultados em relação às demais.

O índice Participação de Capitais de Terceiros (PARTCTERC) demonstra a proporção que existe entre Capitais de Terceiros e Capitais Próprios. De um modo geral, quanto menor for esse quociente, melhor para a empresa, pois menor será seu grau de endividamento e maior será sua liberdade financeira para tomar decisões. Percebe-se que, no que diz respeito a esse índice, a estratégia prospectora apresentou menor média, enquanto a estratégia defensora apresentou a maior média. Desse modo, mais uma vez as empresas prospectoras apresentaram melhor resultado em relação às defensoras e analisadoras.

Por fim, o indicador Rentabilidade do Ativo (ROA) evidencia o potencial de geração de lucros pela empresa. Quanto maior esse índice, melhor, visto que maior será a lucratividade obtida pela empresa em relação aos investimentos totais. Nota-se que a estratégia prospectora obteve maior média, enquanto a estratégia defensora obteve a menor. Logo, as empresas prospectoras apresentaram melhor resultado nesse índice que as defensoras e analisadoras.

De um modo geral, pode-se afirmar que as empresas prospectoras obtiveram os melhores resultados, pois obtiveram menor média no índice Imobilização do Patrimônio Líquido (IMOBPL), maior média no índice Rentabilidade do Patrimônio Líquido (ROE), menor média no índice Participação de Capitais de Terceiros (PARTCTERC) e maior média no índice Rentabilidade do Ativo (ROA). Observa-se ainda que na maioria dos 
casos as empresas defensoras apresentaram os piores resultados.

Assim, os resultados deste estudo corroboram com o estudo de Silva et al. (2015), que concluiu que as empresas prospectoras obtiveram as maiores médias no indicador Rentabilidade do Patrimônio Líquido (ROE), enquanto as empresas defensoras e analisadoras obtiveram as menores médias. Do mesmo modo, corrobora com o estudo de Pletsch et al. (2015), quando menciona que empresas prospectoras tendem a apresentar melhores resultados no que concerne à Rentabilidade do Patrimônio Líquido (ROE). Esse achado também vai ao encontro do estudo de Avci, Madanoglu e Okumus (2011) e Koseoglu et al. (2013) que demonstram que as empresas prospectoras obtiveram melhores resultados.

Por outro lado, este achado não corrobora com o estudo de Jennings, Rajaratnam e Lawrence (2003), que concluiu que não houve diferença significativa entre o desempenho de prospectoras, analisadoras e defensoras.

Após a apresentação do resultado descritivo da ANOVA, tem-se a Tabela 4, que expõe o resultado do teste Tukey, com a finalidade de comparações múltiplas do resultado da ANOVA para diferença de médias entre grupos os grupos estudados.

Tabela 4: Resultado do teste de Tukey

\begin{tabular}{|c|c|c|c|c|c|c|c|}
\hline \multirow{2}{*}{$\begin{array}{c}\text { Variável } \\
\text { Dependente }\end{array}$} & \multirow{2}{*}{$\begin{array}{c}\text { (I) } \\
\text { Estratégia }\end{array}$} & \multirow{2}{*}{$\begin{array}{c}(\mathrm{J}) \\
\text { Estratégia }\end{array}$} & \multirow{2}{*}{$\begin{array}{c}\text { Diferença } \\
\text { média (I-J) }\end{array}$} & \multirow{2}{*}{$\begin{array}{c}\text { Erro } \\
\text { Padrão }\end{array}$} & \multirow{2}{*}{ Sig. } & \multicolumn{2}{|c|}{$\begin{array}{c}\text { Intervalo de Confiança } \\
95 \%\end{array}$} \\
\hline & & & & & & $\begin{array}{c}\text { Limite } \\
\text { Inferior }\end{array}$ & $\begin{array}{c}\text { Limite } \\
\text { Superior }\end{array}$ \\
\hline \multirow{6}{*}{ IMOBPL } & \multirow{2}{*}{2,00} & 3 & $-0,021$ & 0,220 & 0,995 & $-0,549$ & 0,508 \\
\hline & & 4 & $-0,319$ & 0,127 & $0,039 *$ & $-0,624$ & $-0,014$ \\
\hline & \multirow{2}{*}{3,00} & 2 & 0,021 & 0,220 & 0,995 & $-0,508$ & 0,549 \\
\hline & & 4 & $-0,298$ & 0,213 & 0,347 & $-0,809$ & 0,213 \\
\hline & \multirow{2}{*}{4,00} & 2 & 0,319 & 0,127 & $0,039 *$ & 0,014 & 0,624 \\
\hline & & 3 & 0,298 & 0,213 & 0,347 & $-0,213$ & 0,809 \\
\hline \multirow{6}{*}{ ROE } & \multirow{2}{*}{2,00} & 3 & 0,279 & 0,062 & $0,000^{*}$ & 0,130 & 0,429 \\
\hline & & 4 & 0,031 & 0,036 & 0,658 & $-0,055$ & 0,118 \\
\hline & \multirow{2}{*}{3,00} & 2 & $-0,279$ & 0,062 & $0,000 *$ & $-0,429$ & $-0,130$ \\
\hline & & 4 & $-0,248$ & 0,060 & $0,000 *$ & $-0,392$ & $-0,103$ \\
\hline & \multirow{2}{*}{4,00} & 2 & $-0,031$ & 0,036 & 0,658 & $-0,118$ & 0,055 \\
\hline & & 3 & 0,248 & 0,060 & $0,000 *$ & 0,103 & 0,392 \\
\hline \multirow{6}{*}{ PARTCTERC } & \multirow{2}{*}{2,00} & 3 & $-0,983$ & 0,573 & 0,207 & $-2,358$ & 0,392 \\
\hline & & 4 & $-0,712$ & 0,331 & $0,088 * *$ & $-1,506$ & 0,082 \\
\hline & \multirow{2}{*}{3,00} & 2 & 0,983 & 0,573 & 0,207 & $-0,392$ & 2,358 \\
\hline & & 4 & 0,271 & 0,553 & 0,876 & $-1,057$ & 1,599 \\
\hline & \multirow{2}{*}{4,00} & 2 & 0,712 & 0,331 & $0,088 * *$ & $-0,082$ & 1,506 \\
\hline & & 3 & $-0,271$ & 0,553 & 0,876 & $-1,599$ & 1,057 \\
\hline \multirow{6}{*}{ ROA } & \multirow{2}{*}{2,00} & 3 & 0,079 & 0,035 & $0,073 * *$ & $-0,006$ & 0,164 \\
\hline & & 4 & 0,034 & 0,020 & 0,231 & $-0,015$ & 0,083 \\
\hline & \multirow{2}{*}{3,00} & 2 & $-0,079$ & 0,035 & $0,073 * *$ & $-0,164$ & 0,006 \\
\hline & & 4 & $-0,045$ & 0,034 & 0,387 & $-0,127$ & 0,037 \\
\hline & \multirow{2}{*}{4,00} & 2 & $-0,034$ & 0,020 & 0,231 & $-0,083$ & 0,015 \\
\hline & & 3 & 0,045 & 0,034 & 0,387 & $-0,037$ & 0,127 \\
\hline
\end{tabular}

* Significância ao nível de 5\%

** Significância ao nível de 10\%

Fonte: Dados da pesquisa.

Os resultados corroboram com o exposto nas Tabelas 2 e 3. Observa-se que a média do índice Imobilização do Patrimônio Líquido (IMOBPL) é significativamente diferente entre a estratégia 2 (prospectora) e 4 (analisadora), ao nível de 5\%. A média do índice Rentabilidade do Patrimônio Líquido (ROE) é significativamente diferente entre as estratégias 2(prospectora) e 3(defensora) e entre as estratégias 3 (defensora) e 4 (analisadora), ao nível de $5 \%$.

Além disso, no índice Participação de Capitais de Terceiros (PARTCTERC), ao nível de 10\%, a média é significativamente diferente entre a estratégia 2 (prospectora) e 4 (analisadora). No indicador Rentabilidade do Ativo (ROA), a média é significantemente diferente entre a estratégia 2 (prospectora) e 3 (defensora), também ao nível de $10 \%$. 
Cole (2001) menciona que a declaração dos objetivos empresariais e da estratégia adotada para atingir esses objetivos é importante fonte de informação para os investidores, possibilitando-os compreender o negócio e estimar o valor da empresa. Pletsch et al. (2015) aludem que o olhar atento dos investidores no que concerne as estratégias adotadas pelas organizações é importante, pois o investimento gera retorno quando a empresa obtém desempenho satisfatório. Neste estudo, observou-se que a maioria das empresas pesquisadas, no início das negociações no mercado acionário, adotou a estratégia analisadora, combinando os pontos fortes da estratégia defensora e prospectora e, consequentemente, minimizando o risco e maximizando a oportunidade de lucro (MILES et al., 1978).

No entanto, no contexto estudado, as empresas que apresentaram os melhores resultados foram as prospectoras, caracterizadas pela busca e exploração constante de novas oportunidades de produtos e de mercado, prezando sempre pela inovação. Em relação a isso, Oliveira (2004) menciona que com a competição cada vez maior e a integração dos mercados, as empresas precisam observar quais fatores possibilitam maximizar suas chances de sucesso e sobrevivência, no curto e longo prazo. Segundo a autora, um componente essencial na busca por competitividade é a capacidade de criar produtos novos e melhores, de criar tecnologia. Desse modo, as empresas não podem, por muito tempo, serem apenas seguidoras e esperar que alguém inove, devem buscar estar à frente dos concorrentes. Silva et al. (2015) afirmam que a longevidade empresarial pode estar atrelada à proatividade, inovação e a oportunidade de mercado.

\section{Considerações Finais}

Este estudo teve como objetivo analisar a influência das estratégias organizacionais, com base na tipologia de Miles e Snow (1978), no desempenho econômico das empresas que realizaram IPO (Initial Public Offerings) no período de 2008 a 2012. A maioria das empresas, ao iniciarem as negociações no mercado acionário, foi identificada como analisadora com $48 \%$ das observações, seguida das prospectoras com $32 \%$ da amostra e defensoras com $8 \%$.

Os resultados deste estudo demonstraram que as estratégias organizacionais apresentam relação significante com os indicadores Imobilização do Patrimônio Líquido (IMOBPL) e Rentabilidade do Patrimônio Líquido (ROE), ao nível de 5\%. Verificou-se que a estratégia que apresentou melhores médias, nesses índices, foi a prospectora, visto que demonstrou menor média no índice Imobilização do Patrimônio Líquido (IMOBPL) e maior média no índice Rentabilidade do Patrimônio Líquido (ROE). Constatou-se ainda que as estratégias organizacionais também apresentam relação significante com os indicadores Rentabilidade do Ativo (ROA) e Participação de Capitais de Terceiros (PARTCTERC), ao nível de 10\%. Nesses índices, a estratégia que apresentou melhor desempenho também foi a prospectora, pois demonstrou maior média em Rentabilidade do Ativo (ROA) e menor média em Participação de Capitais de Terceiros (PARTCTERC).

A abertura de capital exige que os administradores estejam preparados para atender às expectativas do mercado $\mathrm{e}$ dos acionistas. Este estudo demonstrou que ao iniciarem as negociações no mercado acionário, a maioria das empresas optou pela estratégia analisadora, demonstrando equilíbrio, pois fazem uso dos pontos fortes da estratégia prospectora e defensora. Através dos relatórios de administração, percebeu-se que essas empresas buscam tanto consolidação no mercado em que atuam, quanto expansão do portfólio de produtos e clientes. Assim, demonstram que são mais cautelosas em relação às prospectoras, que dão ênfase à exploração de novas oportunidades de produtos e de mercado, buscando manter a imagem de empresa inovadora.

Cabe salientar que neste estudo também foram identificadas muitas empresas prospectoras e, de um modo geral, essas apresentaram melhores resultados em relação às analisadoras e defensoras. Desse modo, esses achados ratificam o que afirma Oliveira (2004), quando menciona que a inovação é uma característica essencial para o sucesso e sobrevivência organizacional. Considerando a abertura de capital, os investidores passam a analisar os resultados e as organizações procuram alternativas que proporcionem melhores resultados e, consequentemente, retorno para os acionistas. Assim, os resultados deste estudo permitem inferir que o pioneirismo, inovação e busca constante por novos produtos e novas oportunidades de mercado podem desencadear melhores resultados.

Como limitação da pesquisa, menciona-se que não foi possível identificar a estratégia organizacional de três empresas. Além disso, 8 empresas que realizaram IPO no período pesquisado não foram localizadas no site da BM\&FBovespa, por esse motivo foram também excluídas da amostra. Outro ponto a ser considerado foi a subjetividade da pesquisa no que concerne à categorização das empresas quanto às estratégias adotadas, visto que foi realizada por meio da interpretação dos pesquisadores, com base nos preceitos mencionados por Miles e Snow (1978).

Por fim, sugere-se para pesquisas futuras que se faça o mesmo estudo em empresas de um mesmo setor, como o de construção civil, que de acordo com dados da BM\&FBovespa é o setor que se destaca no que diz respeito ao número de empresas que realizaram IPO. 


\section{Referências}

AVCI, Umut; MADANOGLU, Melih; OKUMUS, Fevzi. Strategic orientation and performance of tourism firms: Evidence from a developing country. Tourism Management, v. 32, n. 1, p. 147- 157, 2011. Disponível em: <http:/www.sciencedirect.com/science/article/pii/S026151771000018X>. Acesso em: 15/01/2016.

BM\&FBOVESPA. Como abrir o Capital de sua Empresa no Brasil (IPO): 2011 - Início de uma nova década de crescimento. $1^{\circ}$ edição, 2011. Disponível em:

$<$ http://www.bmfbovespa.com.br/pt-br/educacional/download/BMFBOVESPA-Como-e-por-que-tornar-se-umacompanhia-aberta.pdf $>$. Acesso em: 19/01/2016.

BOMFIM, Lívia Pontes de Miranda; SANTOS, Carolina Macagnani dos; PIMENTA JÚNIOR, Tabajara. Processo de Abertura de Capital de Empresas Brasileiras de 2004 e 2005: razões e percepções. Revista de Administração - R.Adm., São Paulo, v.42, n.4, p.524-534, out./nov./dez. 2007.Disponível em: $<$ http://www.revistas.usp.br/rausp/article/view/44462>. Acesso em: 01/12/2015.

BRANDÃO, Hugo Pena; BORGES-ANDRADE, Jairo Eduardo; GUIMARÃES, Tomás de Aquino. Desempenho organizacional e suas relações com competências gerenciais, suporte organizacional e treinamento. Revista de Administração, São Paulo, v.47, n.4, p.523-539, out./nov./dez. 2012. Disponível em:

$<$ http://www.repositorio.unb.br/handle/10482/16212 >. Acesso em: 13/01/2016.

COLAUTO, Romualdo Douglas; BEUREN, Ilse Maria. Análise de conteúdo das estratégias nos relatórios de administração de companhias abertas. Revista Eletrônica de Administração, Ed. 49, v. 12, n.1, jan-fev 2006. Disponível em:

$<$ http://www.seer.ufrgs.br/read/article/view/40372/0>. Acesso em: 10/12/2015.

COLE, Cathy. J. Communicating key business strategies to investors. Journal of Corporate Accounting \& Finance, $\quad$ v. $13, \quad$ n. $1, \quad$ p. $23-31, \quad 2001 . \quad$ Disponível em: $<$ http://onlinelibrary.wiley.com/doi/10.1002/jcaf.1204/abstract>. Acesso em: 10/01/2016.

DAL MAGRO, Cristian Baú; DOMENICO, Daniela di; HEIN, Nelson. Indicadores de liquidez e solvência da Demonstração do Fluxo de Caixa e os tradicionais: uma aplicação da análise de correlação canônica nas empresas listadas na BM\&FBovespa. Revista de Economia e Administração, v.13, n.1, 97-114 p, jan./mar. 2014. Disponível em:

$<$ http://www.spell.org.br/documentos/resultadobusca/?eou $\% 5 \mathrm{~B} \% 5 \mathrm{D}=\&$ tipo_busca=simples\&campo $\% 5 \mathrm{~B} \% 5 \mathrm{D}=$ TITULO\& texto $\% 5 \mathrm{~B} \% 5 \mathrm{D}=$ Indicadores + de+liquidez $+\mathrm{e}+$ solv $\% \mathrm{C3} \% \mathrm{AAncia}+\mathrm{da}+$ Demonstra $\% \mathrm{C} 3 \% \mathrm{~A} 7 \% \mathrm{C} 3 \% \mathrm{~A} 3 \mathrm{o}$ $+\mathrm{do}+$ Fluxo + de + Caixa $+\mathrm{e}+\mathrm{os}+$ tradicionais $\% 3 \mathrm{~A}+\&$ eou $\% 5 \mathrm{~B} \% 5 \mathrm{D}=\mathrm{E} \&$ campo $\% 5 \mathrm{~B} \% 5 \mathrm{D}=\mathrm{TITULO} \&$ texto $\% 5 \mathrm{~B} \% 5 \mathrm{D}$ $=\&$ eou $\% 5 \mathrm{~B} \% 5 \mathrm{D}=\mathrm{E} \&$ campo $\% 5 \mathrm{~B} \% 5 \mathrm{D}=\mathrm{TITULO} \&$ texto $\% 5 \mathrm{~B} \% 5 \mathrm{D}=\&$ mes_inicio $=\& a n o \_$inicio $=\&$ mes_fim $=\& a n$ o_fim $=>$. Acesso em: 14/01/2016.

DESARBO, Wayne S.; BENEDETTO, C.Anthony Di; SONG, Michael.; SINHA, Indrajit. Revisiting the Miles and Snow strategic framework: uncovering interrelationships between strategic types, capabilities, environmental uncertainty, and firm performance. Strategic Management Journal, Chichester, v. 26, n. 1, p. 47-74, Jan. 2005. Disponível em:

$<$ http://onlinelibrary.wiley.com/doi/10.1002/smj.431/abstract>. Acesso em: 10/01/2016.

FERNANDES, Bruno Henrique Rocha; FLEURY, Maria Tereza Leme; MILLS, John. Construindo o diálogo entre competência, recursos e desempenho organizacional. Revista de Administração de Empresas (RAE), São Paulo, v.46, n.4, p.48-65, out./dez. 2006. Disponível em: < http://www.scielo.br/scielo.php?pid=S003475902006000400006\&script=sci_arttext\&tlng=es>. Acesso em: 13/01/2016.

GIMENEZ, Fernando A. P.; PELISSON, Cleufe; KRUGER, Eugênio G. S.; HAYASHI JR., Paulo. Estratégia em pequenas empresas: uma aplicação do modelo de Miles e Snow. Revista de Administração Contemporânea - RAC, v. 3, n. 2, p. 53-74, 1999. Disponível em:

$<\quad$ http://www.scielo.br/scielo.php?pid=S1415-65551999000200004\&script=sci_arttext $>$. Acesso em: 10/01/2016.

GULINI, Pedro Léo. Ambiente organizacional, comportamento estratégico e desempenho empresarial: Um estudo no setor de provedores de internet de Santa Catarina. Dissertação (Mestrado em Administração), Universidade do Vale do Itajaí - UNIVALI, Itajaí, 2005. Disponível em: < http://siaibib01.univali.br/pdf/Pedro\%20Leo\%20Gulini.pdf>. Acesso em: 12/01/2016. 
JENNINGS, Daniel F; RAJARATNAM, Daniel; LAWRENCE, F. Barry. Strategy-Performance Relationships In Service Firms: A Test For Equifinality*. Journal of Managerial Issues, v. XV, n. 2, p. 208-220, 2003. Disponível em:

$<$ http://www.jstor.org/stable/40604426?seq=1\#page_scan_tab_contents $>$. Acesso em: 11/01/2016.

KÖSEOGLU, Mehmet Ali; TOPALOGLU, Cafer; PARNELL, John A.; LESTER, Donald L. Linkages among business strategy, uncertainty and performance in the hospitality industry: Evidence from an emerging economy. International Journal of Hospitality Management, v. 34, p. 81-91, 2013. Disponível em:

$<$ http://www.sciencedirect.com/science/article/pii/S0278431913000261>. Acesso em: 11/01/2016.

LAVIERI, Carlos Amorim. CARNEIRO DA CUNHA, Julio Araujo. A Utilização da Avaliação de Desempenho Organizacional em Franquias. XXXIII EnANPAD - Econtro da ANPAD. São Paulo-SP, setembro, 2009. Disponível em:

$<$ http://www.anpad.org.br/admin/pdf/ESO3164.pdf > Acesso em: 20/01/2016.

LEONI, José Eduardo Martins; CONTANI, Eduardo Augusto do Rosário; SILVA, Fabiana Lopes da; BERGMANN, Daniel Reed. Ofertas Públicas de Ações e a Crise Financeira de 2008. XVII SEMEAD Seminários em Administração. Outubro. 2014. Disponível em:

$<$ http://sistema.semead.com.br/17semead/resultado/an_resumo.asp?cod_trabalho=1031>. Acesso em: $02 / 12 / 2015$.

MILES, Raymond E.; SNOW, Charles C; MEYER, Alan D.; COLEMAN, JR., Henry J. Organizational Strategy, Structure, and Process. The Academy of Management Review, v. 3, n. 3, pp. 546-562, 1978. Disponível em: $<$ http://amr.aom.org/content/3/3/546.short>.

Acesso em: 10/12/2015.

OLIVEIRA, Letícia de. A estratégia organizacional na competitividade: um estudo teórico. Revista Eletrônica de Administração - REAd, Ed. 40, v. 10, n. 4, jul-ago 2004. Disponível em: < http://seer.ufrgs.br/read/article/view/41883>. Acesso em: 12/01/2016.

PEINADO, Jurandir; FERNANDES, Bruno Henrique Rocha. Estratégia, competências e desempenho em empresas de pet shop: evidências de um levantamento em Curitiba. R.Adm. - Revista de Administração, São Paulo, v. 47, n. 4, p. 609-623, out./nov./dez. 2012. Disponível em: < http://www.revistas.usp.br/rausp/article/view/51908/0>. Acesso em: 10/12/2015.

PLETSCH, Caroline Sulzbach; DAL MAGRO, Cristian Bau; DA SILVA, Alini; LAVARDA, Carlos Eduardo Facin. Estratégias competitivas e desempenho econômico-financeiro de empresas brasileiras. Revista de Contabilidade e Organizações, São Paulo-SP,v. 9, n. 25, 16-30, novembro, 2015. Disponível em: < http://www.revistas.usp.br/rco/article/view/82709/0 >. Acesso em: 15/01/2016.

RIBEIRO, Maitê Garcia Cruz; MACEDO, Marcelo Alvaro da Silva; MARQUES, José Augusto Veiga da Costa. Análise da relevância de indicadores financeiros e não financeiros na avaliação de desempenho organizacional: um estudo exploratório no setor brasileiro de distribuição de energia elétrica. Revista de Contabilidade e Organizações, vol. 6, n. 15, p. 60-79. Ribeirão Preto - SP. Maio-Agosto, 2012. Disponível em:

$<$ http://www.revistas.usp.br/rco/article/view/52657>. Acesso em: 07/01/2016.

RIBEIRO, Osni Moura. Estrutura e Análise de Balanços: Fácil. 10 ed. São Paulo: Saraiva, 2014.

ROSSETTO, C.R., Rossetto, A. M. (2001) O comportamento estratégico segundo a teoria da Miles e Snow: um estudo multicaso em três empresas familiares na indústria da construção civil - setor de edificações. Anais do EGEPE, 2, 821-832. Disponível em: <http://www.abepro.org.br/biblioteca/ENEGEP2000_E0063.PDF>. Acesso em: 16/01/2016.

SAMPAIO, Murilo. A Importância da Inovação no Desempenho dos Processos de Abertura de Capital (IPO) ocorridos no Brasil na última década. XIV SEMEAD - Seminários em Administração. Outubro. 2011. Disponível em:

$<$ http://sistema.semead.com.br/14semead/resultado/an_resumo.asp?pagina=17>. Acesso em: 18/12/2015.

SATURNINO, Odilon; SATURNINO, Valéria; LUCENA, Pierre; CAETANO, Marcelino; FLORÊNCIO, Josete. Oferta pública inicial (ipo) de ações no Brasil: uma análise dos retornos da ipo de ações com baixo índice preço/lucro (p/l). Congresso Latino-Iberoamericano de Investigación Operativa. Simpósio Brasileiro de Pesquisa Operacional. Rio de Janeiro. Setembro. 2012. Disponível em: < https://mpra.ub.unimuenchen.de/48106/>. Acesso em: 17/12/2015. 
SILVA, José Milton Almeida da; FAMÁ, Rubens. Evidências de retornos anormais nos processos de IPO na Bovespa no período de 2004 a 2007: um estudo de evento. Revista de Administração - R.Adm., São Paulo, v. 46, n.2, p.178-190, abr./maio/jun. 2011. Disponível em: < http://www.revistas.usp.br/rausp/article/view/44534>. Acesso em: 05/01/2016.

SILVA, Thiago Bruno de Jesus; LAY, Luís Antônio; SILVA, Marcia Zanievicz da. Estratégias organizacionais e o desempenho econômico-financeiro das empresas cinquentenárias brasileiras. Congresso de Contabilidade 2015 - Universidade Federal de Santa Catarina. Santa Catarina. 2015. Disponível em: $<$ http://dvl.ccn.ufsc.br/congresso_internacional/anais/6CCF/30_17.pdf > . Acesso em: 05/12/2015.

SOARES, Marison Luiz; TEIXEIRA, Omar Raimundo De Paula; PELISSARI, Anderson Soncini. Aplicação da tipologia de Miles e Snow no setor hoteleiro de Florianópolis-SC. Revista de Administração da UFSM, Santa Maria, v. 4, n. 1, p. 251-267, mai./ago. 2011. Disponível em: < https://periodicos.ufsm.br/index.php/reaufsm/article/viewArticle/3338>. Acesso em: 04/12/2015.

SOMAVILLA, Sandra Mara Puhl; MACHADO, Nelson Santos; SEHNEM, Simone. Comportamento Estratégico Segundo a Teoria de Miles e Snow: um Estudo de Caso em um Provedor de Internet do Norte do Rio Grande do Sul. Teoria e Prática em Administração-TPA, v. 3, n. 1, p. 66-95, 2013. Disponível em:

$<$ http://www.biblionline.ufpb.br/ojs/index.php/tpa/article/view/13468>. Acesso em: 05/12/2015.

STEFFEN, Helen Cristina; ZANINI, Francisco Antônio Mesquita. Abertura de capital no Brasil: Percepções de executivos financeiros. Revista Contabilidade\& Finanças - USP, São Paulo, v. 23, n.59, p. 102-115, maio./ago. 2012. Disponível em:

$<$ http://www.revistas.usp.br/rcf/article/view/48083>. Acesso em: 20/12/2015.

TESTA, Carlos Henrique Rodrigues; LIMA, Gerlando Augusto Sampaio Franco de; SECURATO, José Roberto. O desempenho de longo prazo dos ipos: evidências de empresas investidas por fundos de private equity e venture capital. XVI SEMEAD - Seminários em Administração. Outubro. 2013. Disponível em: $<$ http://sistema.semead.com.br/16semead/resultado/an_resumo.asp?cod_trabalho=141>. Acesso em: 05/01/2016.

THOMPSON JR., Arthur A.; STRICKLAND III, A. J.; GAMBLE, John E. Administração estratégica.15. ed. São Paulo: McGraw-Hill, 2008. 668 p. 